\title{
Premiums in Private versus Public Bank Branch Sales
}

\author{
James A. Berkovec \\ Federal Home Loan Mortgage Corporation \\ John J. Mingo* \\ Board of Governors Federal Reserve System \\ Xuechun Zhang \\ American Univerity
}

Draft: June, 1997

\begin{abstract}
$\underline{\text { Abstract }}$
This paper is the first to directly estimate the determinants of differences in premiums received by public and private sellers in the market for bank branches (deposit bases). Deposit premiums received in private sector transactions exceeded those received by the FDIC and the RTC, even after controlling for known characteristics of the transactions and after corrections for possible sample selection bias. The observed differential disappeared by 1992, suggesting improved market efficiency and/or the impact of FDICIA (1991), which mandated "least-cost" resolution procedures for failed institutions. Additionally, the evidence suggests that bank branches are Independent Value Objects whose auctions always result in "unintended" transfers of value to the winning bidders. This result, while consistent with previous literature that found positive Cumulative Abnormal Returns to the winners of auctions for the branches of failed banks, nevertheless suggests that not all of the positive CARs can be due to market inefficiency.
\end{abstract}

*Corresponding author. Address: Mail Stop 153, Federal Reserve Board, 20th \& Constitution Ave., Washington, DC 20551; Telephone: 202-452-3866; Fax: 202-452-5295; e-mail: m1jjm00@frb.gov. The authors wish to thank Allen Berger and Stephen Rhoades for comments on an earlier draft. 


\section{Premiums in Private versus Public Bank Branch Sales}

\section{Introduction and Summary}

During the period 1989 through 1992, at the peak of the U.S. banking crisis, the FDIC and the RTC auctioned off the branch buildings and associated deposit bases of 625 failed banks and 653 failed thrifts, respectively. Observers in the popular financial press (e.g., American Banker, various) routinely viewed these government auctions as "fire-sales," generating sale prices, or "premiums," far below what would have been received in private sector transactions. Generally, the "low" prices were thought to be the result of legal and political pressures on the federal agencies to accomplish quick sales to acceptable bidders.

There is a substantial academic literature that has examined failed bank and thrift auctions (see Section III below.) This literature though has not directly examined whether the government sales of failed banks and thrifts have realized returns lower than would have been achieved by private sellers. Rather, many studies have used event study methodology to test the related question of whether the winning bidders in the auctions show abnormal stock returns. Overall the conclusions of the studies have been mixed regarding whether the FDIC/RTC transactions do, in fact, give away value to winning bidders.

In this paper, we directly examine the difference in prices received by public and private sellers, by comparing the prices received in private sector branch sales and those received in the FDIC/RTC transactions, in cases where the private and public sector transactions were structured in similar fashion. Our analysis does find that the "deposit premiums" (prices) received by the FDIC and RTC from the auctions is substantially lower on average than those received by private sellers of branches. Further, this gap in prices remains after controlling for the known characteristics of the transactions, and after sample selection corrections are used to attempt to control for differences in the "unobservable" characteristics between the public and private sales. The results do suggest that the differences between public and private prices fell over the sample period with only a small and statistically insignificant gap remaining in 1992. The post-1991 result suggests that changes in agency auction procedures, mandated by the Federal Deposit Insurance 
Corporation Improvement Act of 1991, may have contributed to improved sale prices in public-sector transactions (see Section IV below).

The obvious next question after finding that FDIC/RTC premiums are (or were) low is why? One potential explanation is that buyers perceive (correctly or not) that the failed institutions being auctioned by the FDIC/RTC are inferior to the private branches being sold, for reasons that are not correlated with the transaction characteristics in our data sample. Another potential explanation is that the auction procedures employed by the FDIC are inefficient relative to the negotiated transactions used by private branch sellers. This inefficiency could possibly be caused by suboptimal expenditures on marketing and information-dissemination by the FDIC/RTC. The low expenditures (relative to private sector sale expenses) may have led to higher costs of information collection by potential bidders or higher uncertainty in bidders' determinations of value, thus leading to lower clearing prices. Unfortunately, the data do not permit tests of the influence, if any, of sales/marketing expenses or the differential impact of sealed-bid auctions versus negotiated transactions.

The remainder of the paper is organized as follows. Section II provides a brief review of the form of FDIC/RTC transactions vis a vis those of the private sector. The section also describes the database. Section III briefly reviews the literature, including the relevance of auction models. This section justifies the use of a direct pricing model in testing for the existence of unintended subsidies to winners of failed bank branch auctions. The empirical results are presented in Section IV. Section V provides some conclusions.

II. Public and Private Branch Sales; the Database.

The two federal agencies charged with acting as receivers for failed banks and thrifts -- the Federal Deposit Insurance Corporation and the Resolution Trust Corporation -- have several failure-resolution methods at their disposal. ${ }^{1}$ These include total asset purchases and

\footnotetext{
1 The RTC no longer exists. The FDIC is the receiver for any failed bank or thrift.
} 
total liability assumptions by the buyer (so-called "whole bank" deals), as well as variations of more limited transactions in which the buyer assumes only the deposit liabilities (and/or some other, limited non-deposit liabilities), and purchases some limited number of the failed institution's assets (generally, bank buildings and other fixed assets, and readily marked-to-market assets). While complicated whole-bank deals, involving complex government support of asset returns, received much of the research attention, the vast majority of government deals were structured in simple fashion, similar to private sector branch sale transactions (described below).

Banks and thrifts often buy and sell each others' branches in a well documented market. For example, during the period under observation (1989-1992), there were 197 private bank branch sales, and 320 private thrift branch sales. In good times, the branch sale market is at least as robust as during crisis periods -- from 1993 through Q1,1996 there were 619 total bank and thrift branch sales. Institutions sell their branches, and associated deposit bases, for several reasons, including to raise their capital ratios and to improve their operating efficiency. For example, Bank A may find a particular branch to be a loss operation, due to the location and mix of business. However, Bank B may be willing to pay a positive purchase price for the same branch, because of the way it fits into Bank B's branch system. Some large banks routinely consider selling (buying) groups of branches, whenever the calculated rates of return on the associated deposit bases, on a sustained basis, are below (above) internal hurdle rates. ${ }^{2}$

In the typical private branch sale/purchase, the buyer assumes all or most of the deposit liabilities (the customer accounts) associated with the branch. Assets to balance the assumed liabilities consist of fixed branch assets (buildings, etc.), readily marketable assets such as mortgage loans, and cash -- as in the majority of government-conducted branch sales. Generally, the buyer receives from the seller fewer assets (at market value) than the deposit liabilities assumed, the difference being termed the "deposit premium" and representing the

\footnotetext{
${ }^{2}$ See Berger, Leusner, and Mingo (1997) for a complete discussion of branch efficiency and pricing.
} 
seller's profit. The differences between public sector and private sector deposit premiums, if any, are the focus of the present study.

In previous studies, the existence of inefficiencies in public auctions of failed banks or thrifts generally has been inferred through the results of event studies. In these studies, "whole-bank" transactions generally have been mixed together with transactions that may be more narrowly characterized as "branch sales." The existence (absence) of cumulative abnormal equity returns to the winning bidder has been interpreted as meaning that the winner does (does not) obtain an unintended subsidy by acquiring the deposit base of the failed bank or thrift. Also, some studies have examined the efficiency differences across types of FDIC transactions, but not between FDIC (RTC) branch sales and those of the private sector. Finally, a few studies have looked at the influence on FDIC deposit premiums of the number of bidders; but these studies did not compare FDIC premiums with private sector premiums or, with two exceptions, otherwise measure cumulative abnormal equity returns to winning bidders (see Section III following).

We directly compare public sector deposit premiums with those achieved in private sales by using a commercially available database that tracks these transactions for participants in the mergers/acquisitions arena. ${ }^{3}$ The database provides an estimate of the deposit premium in each private and public sale, along with other variables describing the size and structure of the transaction.

\section{Previous Literature and the Pricing Model.}

Event studies based on FDIC failed bank auctions have found mixed results with regard to whether winning bidders receive an effective subsidy. James and Weir (1987), and Bertin, Ghazanfari, and Torabzadeh (1989) found positive cumulative abnormal returns (CARs) in the equity prices of winning bidders in FDIC failed bank auctions. Pettway and Trifts (1985) found negative CARs after an initial positive CARs (with the negative CARs

\footnotetext{
${ }^{3}$ SNL Securities, Inc., Bank M\&A DataSource@.
} 
outweighing the initial positive CARs). Davies (1991) found no relation between winning bids and stock price movements of winning bidders. Billett, Coburn, and O'Keefe (1995) found positive CARs, which nevertheless decreased after $1991 .^{4}$

Studies of failed thrift acquisitions generally found positive CARs (see Cole, Eisenbeis, and McKenzie (1994), Balbirer, Jud, and Lindahl (1992), and Gupta, LeCompte, and Misra (1993), although the results of Gosnell, Hudgins, and MacDonald were mixed. ${ }^{5}$ Note that the FSLIC studies dealt primarily with complex assistance transactions in the period before the RTC failed thrift branch sales began to be structured like, and could be compared directly to, those of the private sector.

Each of the event studies suffers from the problem associated generally with event studies in this context -- conclusions drawn from stock price movements rest on the assumption of information symmetry (i.e., stock market participants understand the nature of an assisted FDIC sale transaction). However, while private sector transactions are analyzed intensively in the financial press, the details of the government transactions are often never widely known, especially in the case of the larger, "whole bank" deals involving complex asset-value supports and associated tax benefits. The effects of the transactions may work their way into equity prices only after long lags beyond the horizon of most event studies. In addition, the event studies generally involved low number of observations (The Davies study and the Billet et alia study had the most observations, 39 and 69, respectively).

Within these previous studies, several reasons are given why the public transactions might entail unintended subsidies to the winners, hence lower prices, than would be observed in private sales. ${ }^{6}$ First the knowledge that the FDIC/RTC generally "must sell" the failed

${ }^{4}$ The Federal Deposit Insurance Corporation Improvement Act of 1991 effectively mandated changes to the FDIC's failure resolution policies, which had the effect of increasing the number of FDIC transactions that were structured as private sector branch sales.

5 The failed thrift studies generaily deait with FSLIC deals (the Federal Savings and Loan Insurance Corporation was the receiver of failed thrifts prior to 1989 when the RTC took over).

${ }^{6}$ Not discussed here are studies that look at the relative efficiencies of differing modes of failureresolution. See Bovenzi and Murton (1988) and Bovenzi and Muldoon (1990) for detailed discussions of resolution modes. Presumably, inefficient modes, arbitrarily chosen by the FDIC or RTC, could impart unintended subsidies to winning bidders. However, Berkovec and Liang (1993) provide empirical evidence 
institutions, accepting the highest nonnegative deposit premium, could influence the bidding strategies of potential buyers. ${ }^{7}$ In contrast, private sellers can choose not to sell if no bid is sufficiently high.

Second, government rules may reduce the competitiveness of the auction by requiring that the winning bidder must be "acceptable" to the government from a prudential standpoint. ${ }^{8}$ This may act to eliminate potential bidders with low capital ratios or other undesirable characteristics, driving down clearing prices. This argument is made notwithstanding the existence of "forbearance" in which low capital banks are nevertheless allowed to bid in failed bank auctions. Further, the usual regulatory scrutiny of private sales may also act similarly in limiting the pool of potential buyers. In addition, potential waiver of antitrust concerns for failed bank sales could even increase the number of potential buyers above those who could participate in private sales.

Studies focused only on gains from winning bids may also be subject to a selection bias by ignoring the costs of submitting losing bids. Many winning bidders bid on more than one transaction. Therefore, winning bids might be structured to cover the costs of failed bids. Event studies, focusing only on the effects on stock prices of winning bids, should therefore see either positive effects (to offset the unseen negative effects of lost bids) or no effects (if the stock market totally discounts the effects of all bids, winning or losing).

Auction theory also suggests that the nature of the object being auctioned could affect prices and CARs. Common-value (CV) auctions, where the value of the auctioned object is

that the majority of FDIC cost differences across transaction types can be attributed to the selection of banks into resolution methods based on observed or unobserved quality differences, leaving little to be explained by relative efficiency of resolution modes.

\footnotetext{
${ }^{7}$ Alternatively, liquidation of the failed bank's deposits effectively entails a negative "premium." That is, the noninterest costs to the FDIC of mailing checks to each depositor are thought to be high enough so that liquidation is considered only when there are no positive bids for the deposit base.

Technically, the FDIC does not "have to sell." Legally, it can create "bridge banks" into which to place the failed bank's deposits. However, long term use of bridge banks is not considered a valid option politically.

${ }^{8}$ In the past FDIC rules limited bidding to firms in the same geographic market as the failed bank, but these rules were removed long before the period under consideration here.
} 
assumed to be the same to all bidders but is unknown at the time of the auction, are subject to the "winner's curse". Failure of bidders to discount bids sufficiently to account for winner's curse will cause prices to exceed values, therefore resulting in negative CARs. Alternatively, in independent private value (IPV) auctions, each bidder knows precisely the value of the object to him -- but this value differs across bidders and the other bidders' values are unknown to each bidder. Optimally, the IPV auction bidder attempts to capture some of the surplus between his own valuation of the object and that of the next highest bidder, by bidding less than the object's true value to him. This underbidding, limited by the uncertainty about the other bids, results in a gain (positive CAR) for the winning bidder. Gilberto and Varaiya (1989), in a study using information on the number of bidders, ${ }^{9}$ conclude that either failed bank branches represent independent private value objects, not common value objects, or bidders are systematically ignoring winner's curse. ${ }^{10}$

Neither CV or IPV objects are inconsistent with government auctions that realize prices equal to those achievable by private sellers. However, if deposit bases are IPV objects, event studies showing positive CARs do not necessarily imply that FDIC/RTC auctions were conducted inefficiently. Further for IPV items, winning bids should be determined by the characteristics of the winning bidder as well as the characteristics of the branch deposit base being sold (including the characteristics of the markets in which the bidders and the branches reside). Bidders' valuations will reflect how the acquired branches fit into their own branch networks, and how the acquisitions might lead to scale, scope, or $\mathrm{x}$-efficiencies, etc. Unintended subsidies stemming from auction inefficiencies, if they exist, could only be detected by direct comparison of FDIC/RTC premiums with those received in similar private sector transactions.

If, by directly viewing the differences in private sector and public sector deposit premiums, we find the public sector premiums to be lower (higher) ceteris paribus, the next

\footnotetext{
9 See also Hirschhorn (1985) and Billett, Coburn, and O'Keefe (1995).

${ }^{10}$ For more detail on auction models, see Riley and Samuelson, (1981).
} 
question is "why?" One possible explanation for low prices in FDIC/RTC sales is underinvestment by government sellers in marketing and information prior to the auction.

Experience with private and public sector transactions suggests that private sellers spend significantly more than does the FDIC/RTC in both marketing the transaction and in providing due diligence information. ${ }^{11}$ Such information includes pre-paid independent appraisals of building values. In the absence of such appraisals, each bidder must separately pay for building appraisals (which reduces, dollar for dollar, the effective bid premium) or, facing uncertainty over the carrying value of fixed assets, bid lower to accommodate the uncertainty. Lower public sector branch deposit premiums could reflect suboptimal marketing and information expenditures on the part of the FDIC/RTC.

IV. Empirical Results.

The data used in this analysis covers both private and public sales of banks and thrifts form 1989 to 1992 . It is crucial to the private sector/public sector comparison to use FDIC/RTC transactions that were structured in similar fashion to private branch sales. Thus, "whole bank" assisted transactions involving asset value supports or putback options were not used for comparison purposes. Only "purchase \& assumption" transactions (without putback options) and/or "deposit transfers" were used. Also, FDIC/RTC transactions with total deposits above $\$ 200$ million were excluded, since large transactions were more likely to be structured with significant asset-value supports (but where the existence of the supports would not necessarily be detected within the transaction database). ${ }^{12}$ Even if no asset-value

\footnotetext{
11 One of the authors served as a financial advisor on several major private and public branch sale transactions. An informal survey of other advisors provided support for the view that private sellers spend more on pre-sale analysis, common information gathering, and marketing.

12 Transactions also were excluded if there were no valid premiums, if no buyer (or seller in the case of private sales) could be properly identified, if no geographic market could be identified, or if key financial data, such as that necessary for the sample selection bias correction, were unavailable.
} 
supports were in place, the transfer to the buyer of a large portion of the failed institution's financial assets could result in implicit discounts (premiums) to the extent the transferring value of the financial assets was substantially below (above) their true market value. To minimize this possibility we also excluded public transactions in which 75 percent or more of the failed institution's assets were transferred to the buyer of the deposit base. The resulting observations, for which all explanatory variables could be calculated, numbered 134 FDIC deals, 271 RTC deals, 51 private bank branch deals, and 64 private thrift branch deals over the four year period. ${ }^{13}$ Table 1 provides a basic description of the data, comparing the different types of transactions. As shown in the table, private sales are larger on average than the public sales of failed institutions. Bank and thrift sales, though, are of very similar sizes for each of the two transaction types.

Deposit premiums (the difference between the deposits assumed by the buyer and the value of the balancing assets, divided by the acquired deposits) average about 1.7 percent and are noticeably higher for private sales than for public sales. For banks, the average deposit premium in private sales is over 2.5 times that for public sales, with the difference somewhat higher for thrift deposit sales. The empirical analysis will determine how much of this difference in deposit premiums between the public and private sales can be explained by the characteristics of the deposit base being sold, the selling firm, and the buying firm. The residual unexplained difference is either due to unobserved differences in these characteristics or due to inherent differences in the sales practices of the public sellers.

Table 1. Data Description

\begin{tabular}{|llllll|}
\hline Transaction Type & Public & & Private & & All \\
\hline Institution Type & Bank & Thrift & Bank & Thrift & All \\
Number of Observations & 134 & 271 & 51 & 64 & 520 \\
Deposit Premium (Mean) & 1.21 & 1.35 & 3.24 & 4.40 & 1.68 \\
Deposit Size (\$Millions, mean) & 38.4 & 47.4 & 119.4 & 114.6 & 60.4 \\
Number of Branches Sold (mean) & 1.7 & 2.1 & 4.9 & 4.4 & 2.5 \\
\hline
\end{tabular}

\footnotetext{
${ }^{13}$ In some cases, transactions involved 2 or more buyers. In each case where an identifiable buyer is recorded, this is treated as a separate observation.
} 
A single regression model for banks and thrifts combined was used to model deposit premiums and to estimate the average premium differential associated with a government assisted transaction. Means and standard deviations for the 25 independent variables in the regression model are shown in table 2. More detailed variable definitions are shown in the Appendix. Coefficient estimates from the regression model are shown in table 3.

Table 2. Variable Means

\begin{tabular}{|llll|}
\hline Variable & Description & Sample Mean & SD \\
\hline & & & \\
BANK & 1 if bank branches being sold & .36 & .48 \\
RATEDIFF & (tbill -cd rate) [3 month] & .52 & .29 \\
STOCK & Nasdaq bank index & 354.15 & 61.14 \\
TGLAM & Mill's ratio * Govt. & -.99 & .75 \\
BGLAM & Mill's ratio * Govt*BANK & -.43 & .80 \\
LLAM & Mill's ratio & -.12 & .16 \\
MARKDEP & Market deposits (\$billion) & 20.09 & 37.7 \\
POPOFF & population/banking office (100s) & 11.72 & 16.9 \\
MIDWEST & midwest dummy & .26 & .44 \\
BANK*MW & BANK*midwest dummy & .052 & .22 \\
SOUTHEAST & southeast dummy & .22 & .42 \\
SAMEMSA & 1 if buyer/seller in same MSA & .37 & .48 \\
BANKSAME & BANK*SAMEMSA & .10 & .31 \\
BUYEQUITY & buyer's equity/assets & .075 & .03 \\
BANKBUY & bank buyin: thrift branches & .52 & .50 \\
CORE & core deposits/total deposits & .81 & .16 \\
GROWDEP & deposit growth rate & -.024 & .15 \\
D1990 & 1990 sale & .28 & .45 \\
D1991 & 1991 sale & .34 & .47 \\
D1992 & 1992 sale & .24 & .43 \\
Govt89 & Government sale in 1989 & .13 & .34 \\
Govt90 & Government sale in 1990 & .22 & .41 \\
Govt91 & Government sale in 1991 & .23 & .43 \\
Govt92 & Government sale in 1992 & .20 & .40 \\
\hline
\end{tabular}

Number of Observations $=520$

The primary variables of interest in the regression are the dummy variables (Govt89, Govt90, Govt91, Govt92) indicating that the observation was a government (public) sale during each year. The results indicate that in all years the deposit premiums received in public sales were, on average, lower than in 'comparable' private sales. This statement, of course, assumes that the control variables in the model do an adequate job of capturing the relevant differences between the characteristics of public and private transactions. The 
control variables that are included in the model can be grouped into 4 basic categories. First there are variables that describe the deposit package being sold and the attractiveness of the market in which the deposits are located. Second, since buyer characteristics may indicate value, there are variables that describe the buyer. Third, there are variables that are associated with the timing of the transaction, and finally there are variables designed to measure and control for possible selection bias.

A primary determinant of the value of the deposit package being sold is the share of core deposits, measured by CORE. Core deposits, defined as deposits in accounts under $\$ 100,000$, are more valuable than other deposits because they are more likely to remain with the branch for a longer period of time and because they are less sensitive to interest rates. As expected, a positive coeflicient for CORE does indicate a higher premium (price) is paid as the percentage of core deposits rises. The other major characteristic of the deposits in the model is the growth rate of the deposits, GROWDEP, measured over the last year before the transaction. Higher growth in deposits over the recent past should indicate a better franchise that will result in continued growth in deposits in the future. The positive coefficient on GROWDEP supports this. A dummy variable, BANK, is also included to indicate that the deposits being sold are from a bank (rather than a thrift). As shown, bank deposits command higher premiums, ceteris paribus, than those of thrifts. ${ }^{14}$

Several variables are entered to describe the attractiveness of the market area where the deposits being sold are located. MARKDEP measures the size of the total deposits in the market area; deposits tend to be worth less in areas with larger quantities of deposits (perhaps because customers are more price conscious in large markets). POPOFF is defined as the population per banking office in the local market and represents a measure of the degree of competition in the area. Higher values for POPOFF reflect less competition and/or more opportunity for deposit growth for the branches that are included in the sale. Regional dummy variables are also included in the model to control for differences in average prices received in different parts of the country. Estimates indicate that premiums were higher in

\footnotetext{
14 The size of the transaction (deposits or number of branches sold) does not statistically affect premiums.
} 
the SOUTHEAST and for thrifts in the MIDWEST. Banks in the midwest, though, are estimated to command lower premiums relative to other banks, as the negative BANK*MW coefficient outweighs the MIDWEST effect.

Characteristics of the buyer included in the model are BUYEQUITY, BANKBUY, SAMEMSA, and BANKSAME. BUYEQUITY measures the equity ratio of the buying firm; buyers with more equity pay higher premiums on average. This result probably reflects the fact that deposit acquisitions are accounted for as cash acquisitions rather than pooling of interests. Therefore, regulatory capital ratios (especially tangible equity ratios) necessarily decline as a result of a deposit purchase. Institutions with higher equity ratios thus can "afford" branch purchases (from a regulatory viewpoint) more than other banks or thrifts. BANKBUY is a dummy variable indicating when there is a bank or bank holding company buyer and a thrift branches being sold. Bank holding company or bank winners of the thrift branches paid $54 \mathrm{bp}$ more for the branches than did thrift winners, in both private and public transactions. Possibly, the banks viewed the thrift acquisitions as providing diversification, or the operating efficiency of the banks generally exceeded those of the thrifts, so that bank winners could be expected to reap greater $\mathrm{x}$-efficiencies (by transforming thrift branches into better performers at any output level) than could the thrift winners. It is also possible the bank winners intended to "cross-sell" the thrift customers an array of "bank-like" products. The variables SAMEMSA and BANKSAME (for bank sellers) indicate whether the buyer and seller are located in the same market. The significant negative coefficient on BANKSAME shows that winners paid less (more) for bank branches if the branches were in the same (different) market as the winner. This effect is not evident for thrift sellers as SAMEMSA has a small (not significant) positive sign. Overall, the fact that buyer characteristics are significant determinants of premiums paid in branch sales is supportive of a conclusion that bank branches are IPV type objects that vary in value between potential bidders.

Deposit premia are expected to vary over time with the value of additional deposits to financial institutions. Consequently the model includes two time varying variables, RATEDIFF and STOCK, along with dummy variables for the different years in the 
estimation sample. RATEDIFF measures the difference between the 3 month t-bill rate and the average 3 month $C D$ rate; the negative sign indicates that premiums increase as $C D$ rates increase relative to t-bill rates. This is consistent with higher $\mathrm{CD}$ rates indicating periods of strong demand for additional deposits. STOCK represents the average value of the Nasdaq bank stock index; higher values of the index are associated with lower average deposit premiums. During periods of high bank stock value, banks can more "cheaply" (in terms of the impact on projected earnings per share) implement acquisitions by buying entire banks in a swap of shares (pooling of interests), thereby lowering relative demand for cash acquisitions such as deposit purchases.

The estimated coefficients on the time dummy variables (D1990, D1991, D1992) indicate that average deposit premiums fall sharply during the sample period, by 3.71 percentage points from 1989 to 1992, for reasons that are not explained by the independent variables in the model. One possible explanation is that, over the period observed, banks and thrifts were under pressure from regulators and the markets to increase their capital ratios and thus general demand for deposit acquisitions (which always result in a lowered capital ratio) fell during the period.

The final set of variables included in the model are the selection bias correction variables. Three variables are included: TGLAM, BGLAM, and JLAM. All three are variants of standard Mill's Ratio sample selection corrections (Heckman, 1979) that estimate the average value of the unobservable component of the premium that could be caused by the "selection" of an observation into the estimation sample. ${ }^{15}$ In our sample, there is concern about several different ways that sample selection could bias results.

First, all of the public sales involve failed institutions, ones that were taken over by the government because of insolvency. An obvious concern is that the deposits of failed institutions are systematically less valuable than the deposits of institutions that do not fail because the event of failure might be partly determined by the value of the deposit base of the depository. Although conceptually this selection does occur, the effect is alleviated

\footnotetext{
15 The formula for the Mill's ratio and the underlying probit models are shown in the Appendix.
} 
because the failure of a depository is always caused by the poor performance of the assets (e.g. defaulted loans) rather than poor quality liabilities, and the degree to which the deposit values of failed institutions is biased is thus uncertain. The model uses two variables to measure and correct for this potential bias. One variable, TGLAM, represents the sample selection effect for failed thrifts, and the other, BGLAM, represents the sample selection effect for failed banks. ${ }^{16}$ The signs of the thrift and bank selection effects differ and neither of the coefficients on these variables is statistically significant.

A second type of selection effect for failed banks could be caused by the process used to resolve failed banks and thrifts. As discussed earlier, the FDIC and RTC used several methods for resolving failed banks, but only the "pure" sales of deposit bases are included in our analysis. Thus, our data sample excludes observations where banks and thrifts were sold via "whole bank" transactions or "purchase and assumption" transactions involving substantial amounts of transferred loans. Rather, in our sample, the main asset types used to balance the transferred deposits were branch buildings, mortgages and other assets transferred at current market values, and cash. As shown in Berkovec and Liang, FDIC procedures for selecting failure methods during 1987 to 1990 did result in a selection of lower-valued institutions that sold in the deposit-only sales. However, it is unclear whether these effects can be expected to result in any empirically important effects on observed deposit premiums in this analysis, since asset quality, not deposit quality, was still the predominant selection criteria used by the FDIC and the RTC. Further, after 1990, fewer of the failed bank resolutions tended to include loan sales with deposits. In any event, ЛLAM is as attempt to measure the selection bias caused by the criteria used to select our estimation sample from the universe of 1989 to 1992 failed bank transactions. ${ }^{17}$ JLAM does not have any significant impact on deposit premiums.

\footnotetext{
${ }^{16}$ TGLAM is the Mill's ratio calculated from an estimated thrift failure model and is entered only for failed thrifts. BGLAM is calculated from a bank failure model and is entered only for failed banks. Various forms of selection effects were tried, including the use of estimated failure probabilities for non-failed sellers. None were found to be significant or have important effects on the GOVT coefficients.

${ }^{17}$ JLAM is the Mill's Ratio calculated from a probit model where failed bank (thrift) transactions are either in or out of the estimation sample.
} 
Selection effects could also occur for the private sales in our sample. After all, private sales should occur only when the buyer values a branch more highly than the seller.

A positive selection bias would result if branch sales occurred when buyers identify branches (of another institution) that are especially valuable to them and are forced to pay premium prices to induce sales. Alternately, private sales could disproportionately consist of distress sales where sellers are selling assets to quickly raise capital, a situation that could lead to a negative selection effect on observed premiums. In the course of this analysis, various efforts were made to identify available characteristics that are associated with private branch sales with the intent of creating selection correction terms for the private sales; these attempts were not successful.

Table 3. Regression Results

Dependent Variable $=$ deposit premium $* 100$

\begin{tabular}{|llcc|}
\hline Variable & Description & Parameter Estimate & T Statistic \\
\hline Constant & & 5.52 & 2.66 \\
BANK & 1 if bank branches being sold & 1.44 & 3.70 \\
RATEDIFF & (tbill -cd rate) [3 month] & -1.34 & -2.00 \\
STOCK & Nasdaq bank index & -.0056 & -1.77 \\
TGLAM & Mill's ratio * Govt & -.190 & 0.86 \\
BGLAM & Mill's ratio * Govt*BANK & .267 & 1.23 \\
JLAM & Mill's ratio & -.031 & -0.05 \\
MARKDEP & Market deposits (\$billion) & -.014 & -2.37 \\
POPOFF & population/banking office (100s) & .031 & 2.30 \\
MIDWEST & midwest dummy & 1.11 & 4.65 \\
BANK*MW & bank*midwest dummy & -1.72 & -4.13 \\
SOUTHEAST & southeast dummy & .56 & 2.85 \\
SAMEMSA & 1 if buyer/seller in same MSA & .17 & 0.81 \\
BANKSAME & BANK*SAMEMSA & -1.00 & -3.04 \\
BUYEQUITY & buyer's equity/assets & 5.43 & 2.13 \\
BANKBUY & bank buying thrift branches & .54 & 2.22 \\
CORE & core deposits/total deposits & 1.73 & 3.06 \\
GROWDEP & deposit growth rate & .96 & 1.97 \\
D1990 & 1990 sale & -2.55 & -3.02 \\
D1991 & 1991 sale & -3.42 & -3.85 \\
D1992 & 1992 sale & -3.71 & -4.19 \\
Govt89 & Government sale in 1989 & -3.18 & -5.26 \\
Govt90 & Government sale in 1990 & -2.38 & -5.59 \\
Govt91 & Government sale in 1991 & -1.43 & -3.68 \\
Govt92 & Government sale in 1992 & -.78 & -1.59 \\
\hline
\end{tabular}

Number of Observations $=520$

$\overline{\mathrm{R}}^{2}=.30$ 
The GOVT variables estimate the remaining effect on deposit premia of government sales versus private sales by year, after controlling for the other observed factors that influence deposit prices. These estimates indicate that there is a substantial negative average effect of government sales on deposit premiums in 1989-1991. The estimated size of the effect declines over time substantially; the estimated premium differential in 1991 is less than half that of 1989. Another 50 percent decline in magnitude is observed for the 1992 estimate, which is also negative but not statistically significant at conventional levels. Overall, these results could indicate that the market discount applied to deposits of failed banks that are sold by the government were substantial but have declined as the market gained more experience with failed institutions and the selling procedures employed by the FDIC and RTC. Also, the disappearance in differential by 1992 suggests that the 1991 Federal Deposit Insurance Corporation Improvement Act of 1991, which mandated "leastcost" solutions to failed banks and thrifts, may have contributed to improved sales efficiency by the government agencies.

An interesting comparison is to examine how much of the observed average differential in premiums remains after the model controls for the effect of the independent variables. This comparison is shown in table 4. Obviously, very little of the observed premium differential is explained by the model. In fact, for the first two years, the estimated government effect is larger than the observed mean premium differential. The model does seem to explain a small portion of the observed differential in 1991 and 192, but the vast majority of the public-private premium differential cannot be explained by the independent variables that describe characteristics of the deposit package, characteristics of the buyer, time, or possible selection bias.

Table 4. Percentage points of observed deposit premium differential explained by model.

\begin{tabular}{|lllll|}
\hline & 1989 & 1990 & 1991 & 1992 \\
\hline Average Private Prem. (\%) & 4.09 & 3.09 & 2.97 & 2.51 \\
Average Public Prem. (\%) & 1.34 & 1.13 & 1.16 & 1.65 \\
Observed Private-Public & 2.75 & 1.95 & 1.81 & 0.86 \\
Estimated Residual Effect & 3.19 & 2.38 & 1.42 & 0.78 \\
\hline
\end{tabular}




\section{Conclusions}

Using a commercially available database, this study is the first to directly compare deposit premiums (purchase prices) in failed bank or failed thrift deposit sales with premiums received in private deposit transactions. Three empirical results are noteworthy:

- During the first three of the four years under observation (1989-1992), FDIC and RTC sales of deposit bases brought significantly lower premiums than similarly structured private sector transactions, other things equal (including corrections for possible sample selection bias).

- The public-private premium differential declined over the four-year period until, in 1992, it was eliminated (in the sense of statistical significance).

- Independent variables peculiar to the winning bidder were statistically significant in determining the level of the winning bid (these variables included the buyer's leverage ratio, whether the buyer was a bank or a thrift, and (for bank buyers) whether the buyer was located in a different market than the deposit base being sold).

Taken together, and in the context of the previous literature on this subject, these empirical results suggest the following conclusions:

- Consistent with popular belief, during the period 1989 through 1991, either the two government agencies were relatively inefficient at the process of conducting "plain vanilla" deposit sales, or the market was slow to assimilate information regarding the existence of a premium differential. Over the four year span, however, the agencies and/or the market learned their lessons. The disappearance of a premium differential in 1992 may also be attributed to the passage of FDICIA in 1991. The Act required the FDIC to pursue "least-cost" resolution procedures and may have induced the agencies to more actively seek marketdetermined solution to the disposition of the deposit bases of failed institutions.

- "Unintended value" accrued to the winning bidders of the failed-bank and failed- 
thrift deposit bases during the period 1989 through 1992 only partially as a result of the agency and/or market inefficiencies. The statistical importance of buyer characteristics suggests that deposit bases are "independent private value" objects, and auction theory suggests that auctions of such IPV objects always entail winning bidders paying less than the true value of the object to the bidder. Thus, to the extent previous event studies found cumulative abnormal equity returns to the winning bidders in government deals, these CARs were only partially due to agency or market inefficiencies.

We can only speculate over the proximate causes of the perceived agency or market inefficiencies - perhaps the FDIC and the RTC did indeed feel political pressure to accomplish quick sales without benefit of optimal marketing expenditures. Whatever the reasons, this study suggests that prices did adjust over time, and, during the next banking crisis, the disposal of the deposit bases of the failed institutions might be accomplished with fewer misallocative effects.

\section{References}

1) American Banker, 1991, "RTC Rigidity Clobbers Taxpayers," November 20, pp. 4 - 13.

2) Balbirer, Sheldon D., G. Donald Jud, and Frederick W. Lindahl, 1992, "Regulation, Competition, and Abnormal Returns in the Market for Failed Thrits," Journal of Financial Economics, 31, pp. 107-131.

3) Berger, Allen N., John H. Leusner, and John J. Mingo, 1997, "The Efficiency of Bank Branches," Journal of Monetary Economics, forthcoming, Vol. 40, No. 1, August, 1997.

4) Berkovec, James A. and J. Nelilie Liang, 1993, "Selection in Failed Bank Auction Prices: An Econometric Model of FDIC Resolutions," Finance \& Economics Discussion Series, Federal Reserve, 93-40.

5) Bertin, William J., Farrokh Ghazanfari, and Khalil M. Torabzadeh, 1989, "Failed Bank Acquisitions and Successful Bidders' Returns," Financial Management, (Summer), pp. 93100.

6) Billett, Matthew T, Jane F. Coburn, and John P. O'Keefe, 1995, “Acquirer Gains in 
FDIC-Assisted Bank Mergers: The Influence of Bidder Competition and FDIC Resolution Policies," FDIC, mimeograph.

7) Bovenzi, John F. and Maureen Muldoon, 1990, "Failure-Resolution Methods and Policy Considerations," FDIC Banking Review, 3, Fall, pp. 1-11.

8) Bovenzi, John F. and Arthur J. Murton, 1988, "Resolution Costs of Bank Failures," FDIC Banking Review, 1, Fall, pp. 1-13.

9) Cole, Rebel A., Robert A. Eisenbeis, and Joseph A. McKenzie, 1994, "Asymmetric-Information and Principal-Agent Problems as Sources of Value in FSLIC-Assisted Acquisitions of Insolvent Thrifts," Journal of Financial Services Research, 8, pp. 5-28.

10) Davies, Sally M., 1992, "FDIC Failed Bank Auctions," Federal Reserve Board, mimeograph.

11) Gilberto, S. Michael and Nikhil P. Varaiya, 1989, “The Winner's Curse and Bidder Competition in Acquisitions: Evidence from Failed Bank Auctions," Journal of Finance, XLIV, no. 1, March, pp. 59-75.

12) Gosnell, Thomas F., Sylvia C. Hudgins, and John A. MacDonald, 1993, "The Acquisition of Failing Thrifts: Returns to Acquirers," Financial Management, Winter, pp. 58-68.

13) Gupta, Atul, Richard L. B. LeCompte, and Lalatendu Misra, 1993, "FSLIC Assistance and the Wealth Effects of Savings and Loan Acquisitions," Journal of Monetary Economics, 31, pp. 117-128.

14) Hirschhorn, Eric, 1985, "Bidding Levels in Purchase and Assumption Auctions," Proceedings of the Conference on Bank Structure and Competition, Federal Reserve Bank of Chicago, May, pp. 369-388.

15) James, Christopher and Peggy Weir, 1987, "An Analysis of FDIC Failed Bank Auctions," Journal of Monetary Economics, 20, pp. 141-153.

16) Pettway, Richard H. and Jack W. Trifts, 1985, "Do Banks Overbid When Acquiring Failed Banks?" Financial Management, 14, pp. 5-15.

17) Riley, John G. and William F. Samuelson, 1981, "Optimal Auctions," American Economic Review, 71, June, pp. 381-392. 


\section{Appendix}

A. Variable definitions:

\begin{tabular}{|c|c|c|}
\hline BANK & $=$ & 1 if bank branches being sold; 0 if thrift branches. \\
\hline RATEDIFF & $=$ & $\begin{array}{l}\text { Difference between daily average } 3 \text {-month T-bill and CD } \\
\text { rates for the calendar month of the announcement date. }\end{array}$ \\
\hline STOCK & $=$ & NASDAQ Bank Stock Index on the announcement date. \\
\hline MARKDEP & $=$ & Market deposits (\$billion) as of mid-year prior to announcement date. \\
\hline POPOFF & $=$ & $\begin{array}{l}\text { Population per banking office in MSA during census year prior to } \\
\text { announcement. }\end{array}$ \\
\hline MIDWEST & $=$ & $\begin{array}{l}1 \text { if branches sold are in Midwest, } 0 \text { otherwise; MW includes the states } \\
\text { of IA, IL, IN, KS, KY, MI, MN, MO, ND, NE, OH, SD, and WI. }\end{array}$ \\
\hline SOUTHEAST & & $\begin{array}{l}1 \text { if branches sold are in Southeast, } 0 \text { otherwise; SE includes states of } \\
A L, A R, F L, G A, M S, N C, S C, T N, V A \text {, and WV. }\end{array}$ \\
\hline SAMEMSA & $=$ & $\begin{array}{l}1 \text { if buyer and "seller" have branches in the same MSA prior to } \\
\text { announcement; } 0 \text { otherwise. }\end{array}$ \\
\hline BUYEQUITY & $Y=$ & $\begin{array}{l}\text { The buyer's tangible equity to total asset ratio; quarter-end prior to } \\
\text { announcement. }\end{array}$ \\
\hline CORE & $=$ & $\begin{array}{l}\text { Deposits in accounts less than } \$ 100,000 \text { divided by total domestic } \\
\text { deposits, quarter end prior to announcement. Ratio calculated for the } \\
\text { sold branches, when possible; otherwise, for "seller" in the aggregate. }\end{array}$ \\
\hline GROWDEP & $=$ & $\begin{array}{l}\text { Percentage growth rate of branches, proxied by growth rate of } \\
\text { "seller's" domestic deposits during year prior to announcement. }\end{array}$ \\
\hline ЈLAM & $=$ & Mill's ratio. \\
\hline BGLÀMí & $=$ & $\begin{array}{l}\text { Mill's ratio* Govt (where Govt }=1 \text { if FDIC/RTC transaction in } \\
\text { any year, } 0 \text { otherwise). }\end{array}$ \\
\hline TGLAM & $=$ & Mill's ratio*Govt*BANK. \\
\hline
\end{tabular}


B. Probit Models for Calculation of Mill's Ratios.

The probit model underlying the Mill's ratio calculation is as follows:

$\mathrm{P}=\mathrm{f}($ CAMEL88, DELTCAM, AST88, GROUP, GAS) where

$\mathrm{P} \quad=\quad 1$ if failure occurred during the observation period, 0 otherwise.

CAMEL88 = Institution's composite "CAMEL" supervisory rating during 1988.

DELTCAM = Change in the CAMEL ratio from 1987 to 1988 .

AST88 = Total assets in 1988, as of the examination date; in \$millions.

GROUP $=1$ if institution's total assets exceed $\$ 500$ million at 1988 exam date.

GAS $=$ GROUP*AST88.

The probit model is estimated separately for banks and for thrifts. Parameter estimates and standard errors are shown below for each of the two probit equations. Bank Failure Prediction Model.

\begin{tabular}{lcl}
\hline Variable & Estimate & Std. Error \\
\hline INTERCEPT & 3.87 & .094 \\
CAMEL88 & -.714 & .027 \\
DELTCAM & .216 & .047 \\
GROUP & -.523 & .133 \\
ÁST88 & -.0017 & .0003 \\
GAS & .00171 & .00034 \\
\hline
\end{tabular}

Thrift Failure Prediction Model.

\begin{tabular}{lcl}
\hline Variable & Estimate & Std. Error \\
\hline INTERCEPT & 5.19 & .208 \\
CAMEL88 & -1.11 & .056 \\
DELTCAM & -.132 & .120 \\
GROUP & -.335 & .188 \\
AST88 & -1.157 & .712 \\
GAS & 1.21 & .713 \\
\hline
\end{tabular}

